\title{
SOCIO-ECONOMIC CONSCIOUSNESS IS A KEY DRIVER OF THE TAX SERVICE OF UKRAINE
}

\author{
Natalia Riabinina ${ }^{1}$
}

\begin{abstract}
At the intersection of the past and the future there is a point of present, which, due to external and internal socio-economic requirements, activates the subject himself. In the interrelational phenomena of economic consciousness, which bears its personal direction and in manifestations of external economic activity of the subject, acting as a regulator, relying on empirical studies of a dialectic nature, one of the main studies of our time is economic behavior. All factors are unifying, coordination or contradictions of economic consciousness and behavior still act as a dynamic factor for development and progress, which is a key vector of human-tax relations. Without an individual vision of the universe, the present, personality problems cannot be covered and seen by all sides of economic and social society, based on trust and reliability. The level of trust and reliability characterizes the quality of economic and social consciousness of citizens, business, representatives of enterprises, which manifests itself and increases in the development of the interrelationships of civil society and carries results for the tax service. Formulation of the goals and objectives of the article (setting a task). A large amount of research on social consciousness, a wide and varied direction of studying the direction and connection with other disciplines helps to more closely reveal the problems of society and the individual. The purpose of the study is to separate and determine the individuality of a person in the process of economic and social consciousness, attitude and manifestations of personality and group behavior at all levels of this concept, analysis, specificity and structural content exactly inherent in the tax component. Methodology. During the study, to study and achieve the goal, the analysis of theoretical aspects and generalizations of scientific sources, dialectical cognition of formation and manifestations of social consciousness of a person when paying taxes, found a kind of economic concept, methods of induction and deduction, abstraction of theoretical provisions and dialectic cognition were carried out. Results. The article raises the issue of the importance of social consciousness of the country's tax service for further socio-economic growth and improvement of people's lives, on the basis of intergroup and interpersonal interactions and relationships at a high micro level, on the foundation of trust and cooperation between society and government, unified work and development of state, economic, civic platforms. It is with a person that the mechanism of development, accumulation and effective use begins, so it is the social consciousness of the individual that carries the basis for the further development of the state. The analysis of elements and component of socio-economic consciousness in the individuality of a person in the economic system is carried out and the main components, such as trust and reliability, are determined. The analysis of economic behavior of the individual when making a rational decision in the world of economic changes of the tax service is carried out. The practical component of the main provisions of the concept and levels of social consciousness, and its role in the general concept of the economic component can further develop and be used in the process of developing the analysis and development of the individual with individual behavior and personal decision-making for the fiscal service when paying taxes. Value/originality. The theory of socio-economic consciousness itself is not new, but the direction of study and application of individual characteristics of taxpayers is new and little researched, so it gives a new impetus to interest and further development of the detection of theoretical aspects, generalization to definition and essence, outlining the main directions of development and formation for the future.
\end{abstract}

Key words: socio-economic consciousness, behavioral economy, tax service, trust and reliability, tax culture, quality of life.

JEL Classification: E71, A14, D71, O35

\footnotetext{
Corresponding author:

${ }^{1}$ University of the State Fiscal Service of Ukraine, Ukraine.

E-mail: riabininano@gmail.com

ORCID: https://orcid.org/0000-0001-8378-4485
} 


\section{Introduction}

At the end of the last century, the influence of geopolitical factors, difficulties in creating market relations, financial crises, neglect of local and national institutions, contributed to the impetus for recognizing the problems of correctness of social and economic decisions. State taxes have always been an urgent topic of society, for the development and further prosperity of the country, so the role of the state and its political and legal component on the moral duty and behavior of a citizen is one of the pressing issues of our time. The multi-vector component of the economic activity of economic entities is aimed at improving the quality of life of the population, because it is the person who stands at the beginning of the development of society, having at the heart of the platform the trust and reliability of citizens to the state and government. One of the indicators of trust in the state is the level of public consciousness and tax culture, which is reflected in the self-organization of payment of taxes and the organization of labor in the tax authorities of the country. Today in modern Ukraine there is a shortage of such trust, and this, at the same time, inhibits the formation of human social consciousness. One of the tasks of the tax service is to achieve social equality and exclusive attitude to the needs of society, and achieving the effectiveness of the tax service depends on overcoming the negative attitude of business entities.

\section{The main components of consciousness}

The breadth of phenomena and concepts of socioeconomic and psychological science, which has long traditions, theoretical explanations, can be combined into two directions: the phenomenon of economic consciousness with elements (intentions, thoughts, assessments, ideas, etc.) and economic behavior, it is individual and group direction that has been studied and analyzed in recent years widely and effectively. The main components of consciousness are cognitive (various forms of knowledge about social objects), emotionally evaluated (attitude and compassion for social objects) and behavioral (readiness and decisionmaking behavior in the relationship of social objects - motives, intentions, expectations, etc.) we have been clearly observed in recent years when analyzing the results of specific empirical studies, examples of which are: property, material well-being, poverty, wealth, money and attitude to them, types of economic activity, readiness of the individual for self-reliance, social adaptation of the unemployed, psychology of advertising, marketing and others confirm the universality of the structure of economic consciousness phenomena, despite the specific content of those socioeconomic objects and phenomena that are displayed in it. In making a detailed analysis, it is possible to distinguish similar natural trends that combine all the main components of consciousness and can confirm the existence of both basic, unchanged elements of the structure and more superficial, local characteristics, the influence of which can be externally. However, the manifestations and development of economic consciousness should be investigated not only in the external environment, as changes in the composition of ideas, modality of relations, level and direction of behavioral readiness, etc., but also manifestations of internal transformations and contradictions of psychological changes and its elements: the study of the past and the analysis of the new, assessment of changes in social norms, readiness for action, intentions of the individual and others that are currently a problem and vision of serious scientific comprehension. "Economic consciousness should be understood as a systemic component of consciousness, a higher level of mental reflection of economic relations by a person." (Deineka, 2000). By dividing the economic consciousness into an individual (the individual is manifested and purposefully acting, with her creative transformations and impressions, relying on personal experience), group (generalized consciousness based on the purpose of combining the group's ideas and opinions on decision-making and decision-making), and the mass (public consciousness on economic issues that concern people, are of great importance and bear decisive, alternative consequences) we gradually draw comparisons and analysis, inherent personality to a wider mego equality, uniting society as a whole.

\section{Elements of economic consciousness}

Economic consciousness is extremely necessary when studying the internal state of a person, because without knowledge of mental manifestations we will not be able to fully understand behavior and decision-making. The structure of economic consciousness consists of economic emotions and feelings (satisfaction from work or process, craving for knowledge, a sense of pride and respect, excitement, risks, overcoming fears), perceptual economic behavior (attitude and promotion of money, goods, services, advertising, consumer psychology) and economic ideas and thinking (representation of the function and work of the economic sphere, phenomena, laws).

The economic behavior of the individual is us to focus on the presence of people of limited intervals of attention, so the tax procedure must be simplified and made accessible, because non-payment of taxes leads to an increase in inequality. Excessive complexity of taxation, the ability of excess concentration and misunderstanding of taxation can lead to the fact that a disciplined person, with noble intentions, will not pay contributions to the state pocket. By examining the effectiveness of a behavioral economy that helps 
simplify citizens' collection of tax information, calculation of payments and tax risks, we can also investigate moral risks. Imagine the dangerous practice of granting tax amnesty, which involves reducing fines and interest. Human attitudes can change co-ordinated when a person understands that fines for non-payment can be weakened or changed simply by ignoring the rules and looking at uncontrolled by state authorities, completely stop paying, which leads to a reduction in tax revenues in the future. In this situation, it is possible to operate with court sanctions with further consequences.

\section{Economists of consciousness and international education}

Behavioral economists, studying the role of human consciousness, and voxCheck International Education (2014) looked at and investigated the dependence of tax liability of citizens and the possibility of raising public awareness.

The economist James Andreoni (1998, 2002) revealed the importance of the psychological factor in the tax sphere, arguing that human emotions such as shame, duty, guilt, national character traits, demographic, social and moral components need to be adapted and integrated into traditional economic models. One of the main topics of the tax component is the tax collection system. Sometimes, the taxman, from the very beginning, considers a citizen as a fraudster and a potential non-payer, which also contributes to the negative attitude of society to tax authorities and then to pay taxes. Professor of Economic Psychology Erich Kirchler (2011) criticized the method of "criminal and police", which should be coordinated to a more loyal approach, using the method of "client and eternal service". Research by economist James Alma (20012, 2014) proved that high tax rates on equal terms also do not contribute to a healthy climate of tax morality and discipline, the more incorrect, harsh punishment for non-payment of taxes and unclear control of fiscal authorities.

Conducting behavioral experiments with students from 34 countries on bribery, Abigail Barr and Danila Serra, (2010) found a link between tax liability with elements of bribery and the influence of the cultural environment and norms of their country's behavior. Bribes aimed at tax evasion, the person who abuses it, reduces the social norms and values of the society in which he lives and develops. In economics, everything is interconnected. Tax evasion gives impetus to the growth of the shadow economy, which in turn leads to pressure on the economy and social benefits. More often, the state shifts the entire burden of budget execution to conscientious payers, and sometimes, by increasing tax pressure or increasing tax rates, takes away the latter from entrepreneurs.
In the 90s, an Australian model appeared, which took as a basis the concept of "motivational position". People who constantly ignored and refused to pay were blacklisted by fiscal authorities. were constantly under the control of the authorities, and, if necessary, applied court proceedings. Undisciplined payers were punished with fines and audits.

The basis of tax policy is to maintain responsibility through educational initiatives, the comfort of accounting and the convenience of the tax system. Northern European countries use the BISER model, which consists in deep behavioral analysis from the beginning of each person's tax history, its encouragement to cooperate with the tax service. In the UK, behavioural economics teams are working in the tax departments to study tax behaviour, methods to stimulate fiscal payments and build social tax regulations. In the Netherlands, we observe a model of "horizontal monitoring", which is based on the signing of a mutually beneficial agreement between the tax authority and the administration, which affects mutual understanding, cooperation and trust. In Sweden, the model is used "from the very beginning", which is an example of the government's use of broad information and a coherent idea of the tax system itself, its work, the end result and prospects among citizens.

\section{Problems of the tax service}

How to inform the Ukrainian people that payment of taxes is necessary and mandatory for the country and our economy? Studies were carried out on warning letters, which reported on inspections of tax reports and the results were predictable: low and middle income taxpayers increased the amount of declared income, and with high incomes ignored the situation. Such a study was conducted in a European country. When the issue of fines and their sizes are raised, the opinions of tax authorities and economists differ, because the study on fines did not bring a single result, but the conclusion that effective and optimal fines work only in combination with broad audit control is correct. Recently, we have seen interest in studying behavioral experiments in the field of taxation and tax authorities. Behavioral economists can offer society a model of fiscal policy behavior.

Analyzing the study of research and practices in the behavioral economy of different countries, you are once again convinced that punishment and strict administrative methods for stimulating citizens to pay taxes are not fruitful and correct. Sometimes, an unobtrusive reminder, a friendly and calm response of the taxman, a high service of the tax system is enough for a positive result. Stimulation and "motivation is a set of internal and external driving forces that encourage a person to activity and set the orientation, boundaries and forms of this activity focused on achieving a certain 
goal." (Vikhansky, Nausov, 2003). And the painful topic of Ukrainian society is the return and fair use of citizens' money in the form of high-quality social benefits. The question becomes why at such high tax rates, in a country where corruption flourishes and tax evasion is the norm, conscientious taxpayers bear the full burden of the tax system.

Society sees a connection between the tax service and the welfare of citizens. Citizens pay attention to the quality of fiscal services. If social reimbursements are low and inefficient and the quality of public benefits does not correspond to the understanding and vision of society, then tax payments are perceived as unfair and the citizen refuses to pay them. The low average size of the return of social benefits per capita entails a loss of trust in the state, injustice and tax internal protest. "The main task is to carry out tax restructuring in such a way as to cause the least damage to the revenues of the state budget (the so-called income neutral tax shift) and incentives for labor and investment... it is necessary to carry out a general redistribution of the tax burden by applying the entire list of taxes, their elements (taxpayers, objects, base, benefits, rates, etc.), rather than gross actions, jeopardizing budget revenues, abolishing some taxes and introducing unknown things. A sign of a healthy tax policy is the stability of the tax system during the crisis" (Schwabi 2020).

\section{Tax culture}

Tax policy is the main component of the welfare of society and the state, informing and supplementing the population with a culture of taxation in the socioeconomic sphere, forming the tax behavior of all participants in the process. "Taxes not only helped create the state. They contributed to the design of it. The tax system became the body whose development caused the appearance of the second bodies" (Shumpeter, 1918). The taxation process and development are greatly influenced by the level of tax culture. The problems of low tax culture are social contradictions that carry unfair distribution of income in society with devant forms of tax behavior and contradictions of the interests of the state, regulating socio-economic processes through taxation, low living standards of the majority of the population, which deteriorates in the conditions of economic crisis and growth of the shadow economy. Tax culture is a complex socio-economic phenomenon inherent in a society with a market economy, the level of which causes the fiscal potential of the state. The concept of "tax culture" first appeared more than 85 years ago, in an article by the prominent economist and sociologist J. Shumpeter (1883-1950), the author of the concept of "tax state" "Economics and sociology of income tax", noting that "tax culture is an expression of human spirituality and creativity aimed at increasing the level of tax consciousness of society" (Shumpeter, 1918). Research in the field of tax culture to the majority was considered comprehensively, without studying the intricacies of tax behavior. Fairness, honesty, fulfillment of professional duties, promoting the revival of taxpayers' trust in state bodies is the main goal of creating ethical standards of conduct for employees of tax authorities. "Today we are forming a new tax service, in which there is zero tolerance for corruption, and employees are professionals who adhere to a high culture of communication with taxpayers, and taxpayers, in turn, respect the profession of the tax officer." (Verlanov, 2019).

The topic of paying taxes has always been painful and has been in the spotlight. There is still no reasonable and explanatory answer as to why it is preferred to work in the shadows and wages in the envelope satisfy employees. In the labor market in Ukraine, all employed people who are not legally or in fact not subject to national labor legislation, laws of the taxation and social protection system approximately $21.6 \%$, which is about 3.5 million. Persons. State authorities are not able to regulate the process because it goes beyond their competencies and legislation. According to statistics, Ukrainians are in no hurry to share information about their own income with the state, preferring salary in cash envelope and withdrawal of money abroad, although the Parliament has repeatedly approved zero declaration bills (one-time legalization of hidden income).

\section{Interaction of the taxpayer with the state}

The main stable source of revenues to local budgets is the entrepreneurial activity of individuals. The functions of the modern STS change according to the functional principle, taking steps to prevent fiscal risks and initiate unified approaches to their detection, dividing the work of tax authorities into several areas: risks in the audit. risks with VAT refunds, risks in excises, etc. Tax management, working on reforming the administrative and territorial structure, reducing the number of points of tax services, understands that all innovations will affect the structure of the authorities. Article 58 of the Tax Code provides for the content of the tax notice - by the decision of the State Tax Service on additional non-payment to the payer, a fine, a penalty, which must be finalated in full, according to all the clarifying circumstances of the charges. For reasons of minimization and VAT refund, the painful issue in terms of risks at the end of 2019 is VAT, followed by excise duty, in particular, shortage in the tobacco industry, sale of fuel and ethyl alcohol. The third risk is associated with rent. For example, this applies to gas prices, which is a painful topic for the majority of the population, especially socially vulnerable. Simplifying the payment of taxes consists not in the amount of taxes, but in the plane of 
simplification of administration, which can be carried out due to digitization and electronicization, which will lead to a normal, comfortable tax system. The material and legal component of tax law and taxation should be fair: equal income - equal taxes, high incomes - high taxes. Article 212 of the Criminal Code - tax evasion, having 900 thous. Uah. threshold for criminal liability. To raise the topic of taxes and their number, first of all, we need to look at the problem frankly and without lies, saying that there are nine taxes on in fact in each tax three more taxes (property tax has: land tax, property tax, transport tax). Communication between the tax service of the country and business in our time, it is unfortunate to state this as the relationship of enemies, criminal and police officer, while in civilized countries the attitude is open and transparent, everyone pays taxes, the same and all this contributes to the development of the economy. The only requirement of white business is equal conditions: BEPS and the exclusion of the use of pseudo-FLP (limit set by the FLP), which is often used in restaurants and hotels, by using an electronic check, downloading the tax service program. A person who has a turnover of 5 million HRYVNIA per year and at the same time does not have questions in the tax office, can work on a simplified taxation system using the single tax model, if this amount is per day, then you need to pay taxes fairly without shadow schemes and in case of fraud they are waiting for verification, a rate of $15 \%$ and a refusal of a single tax. The tax amnesty is planned to work in a package with BEPS and ratification of the agreement on the automatic exchange of tax information, which is likely to be paid, a single rate of $5 \%$. Reduced $-2.5 \%$ when investing in government bonds. The purpose of amnesty is to allow people to bleach in front of the state and return funds to Ukraine and replenish the budget, although 300 thousand hryvnias will be amnesty for everyone. Amnesty is a voluntary declaration. In the modern economy, "black" lyle is cheaper than "white". "It is necessary to highlight the weight of human motivation in the struggle of human consciousness between rationality and irrationality, therefore, the study of human behavior in the context of individual and social formation is inextricably linked with the study of its feeling as a member of a democratic, legal and social society" (Hurochkina \& Kravchenko, 2020). Ukraine needs a new state policy to build a fair and stable tax system, protecting the fiscal interests of the state and the social needs of taxpayers, reducing tax pressure and the number of inspections. Over the years of independence, Ukraine has gone a difficult way of becoming a state and the tax system and politics are also replaced by constant reform, dictated by the deficit of budget funds and the unevenness of tax revenues to the budget. Increasing the tax rate is not an urgent topic, so in modernity all prerequisites for the development of other segments of tax activity are created - finding reserves for reducing the tax burden and increasing income by increasing tax discipline and the level of tax culture in society, strengthening administrative and criminal liability for tax offenses. The concept of "tax culture" is traced in European science as a result of the unification of common philosophical, sociological and economic concepts of culture and tax and there is still no single definition.

\section{Conclusion}

An important element of human economic consciousness research when paying taxes is the social policy of the state, namely improving the efficiency of education, health care and other branches of the socio-cultural sphere, which will destroy the negative impact of external factors and simplify the decisionmaking process of everyone. And this is impossible without the tax authorities of the country. Taxes in the system are perceived as an objective loss, not a social responsibility. Fiscal discipline of a business or an individual, all attempts by the authorities to introduce social responsibility within the framework of tax reform is perceived negatively. The ability to put common interests above personal ones is still the rules of more conscious socio-market systems. That is why the greatest attention in scientific research should be concentrated on the problems of making economic decisions taking into account the tax culture and public consciousness when paying and administering taxes.

\section{References:}

Alm James (2012). Developing Alternative Strategies for Reducing Tax Evasion 2012/7/30 book Tax Evasion and The Shadow Economy by Edward Elgar Publishing. Available at: https://www.researchgate.net/profile/ James-Alm/publication/280019814_Designing_alternative_strategies_to_reduce_tax_evasion/links/ 56606af908aebae678aa112e/Designing-alternative-strategies-to-reduce-tax-evasion.pdf

Alm James (2014). Expanding the Theory of Tax Compliance from Individual to Group Motivations 2014/3/28 Book Directory on Alternative Theories of Public EconomicsbyEdwardElgarPublishing. Available at: https://scholar.google.com/citations?user=NaCGaF4AAAAJ\&hl=en

Andreoni James, Brian Erard, \& Jonathan Feinstein (1998). Tax Compliance. Journal of Economic Literature, vol. 36, no. 2, pp. 818-860.

Andreoni James, \& John Miller (2002). Giving According to GARP: An Experimental Test of the Consistency of Preferences for Altruism. Econometrica, vol. 70, no. 2, pp. 737-753. 
Barr, Abigail \& Serra, Danila (2010). Corruption and culture: experimental analysis. Journal of Public Economics, Elsevier, vol. 94 (11-12), pp. 862-869, December.

Deineka, O. S. (2000). Economic Psychology: A Textbook. St. Petersburg University: S.-St. Petersburg University Publishing House, 160 p.

Hurochkina, V. V., \& Kravchenko, L. V. (2020). Principles and patterns of development of industrial enterprises in the energy economy. Market Infrastructure, vol. 42.

Kirchler, E., \& Rodler, K. (2011). Motivation in organs / Psychology of labor and organizations psychology; t. 1. Kh.: Yzd. "Humane Center", 144 p.

SCHUMPETER Joseph Aloisius (1918). Die Krise der Steuerstaates 1918 № 4 of Zeiqragen azu dem Gebiet der Soziologie. An English translation, by Wolfgang F. Stolper and Richard A. Musgrave, appeared (1954) in Internationa lEconomic Papers (n. 4). Available at: https://edisciplinas.usp.br/pluginfile.php/5322348/mod_ resource/content/1/Crise\%20do\%20Estado\%20Fiscal.pdf

Verlanov, S. (2019). EU Program "Support to Public Finance Management for Ukraine - EU4PFM" Head of the State Tax Service of Ukraine State Fiscal Service of Ukraine 30.05.2019. Available at: http://sfs.gov.ua/mediatsentr/novini/380379.html

Vihansky, O. S., \& Naumov, A. I. (2003). Management. Student. 3rd out. Moscow: Gardaryks, 528 p.

VoxCheck (2014). VoxCheck: forces politicians to tell the truth 2014 Greatidea. Available at: https://biggggidea.com/project/voxcheck/

Shvabiy, K. (2020). COVID-19, budget deficit plus offshore all the country.Did the authorities initiat another tax reform on time. Available at: https://zn.ua/ukr/internal/covid-19-byudzhetniy-deficit-plyus-ofshorizaciyavsiyeyi-krayini-345056_html 